Check for updates

Cite this: Org. Biomol. Chem., 2020, 18, 7545

Received 2nd September 2020, Accepted 14th September 2020

DOI: 10.1039/d0ob01815e

rsc.li/obc

\section{Dealkoxylation of $\mathrm{N}$-alkoxyamides without an external reductant driven by Pd/Al cooperative catalysis $\uparrow$}

\author{
Hirotsugu Suzuki, (D) Takahiro Shiomi, Kenji Yoneoka and Takanori Matsuda (D)*
}

Lewis acid-assisted palladium-catalysed dealkoxylation of $\mathrm{N}$-alkoxyamides has been developed. This reaction proceeded smoothly with a range of $\mathrm{N}$-alkoxyamides in the absence of an external reductant, thereby establishing a convenient and reductant-free protocol. In addition, a gram-scale reaction could be achieved. Preliminary mechanistic investigations indicated that $\boldsymbol{\beta}$-hydrogen elimination from a palladium alkoxide intermediate generated an intramolecular hydride source.

$\mathrm{N}$-Alkoxyamides are an important class of synthetic intermediates for a range of organic transformations. ${ }^{1}$ In particular, $N$-methoxy- $N$-methylamides, which are known as Weinreb amides, have unique properties as acylating reagents that suppress the overalkylation of reaction products by forming remarkably stable five-membered cyclic intermediates (Scheme 1a). ${ }^{2}$ This exceptional feature allows the transformation of readily available and stable $N$-alkoxyamides ${ }^{3}$ into useful aldehydes and ketones in a single step. Recently, $\mathrm{N}$-alkoxyamides have emerged as versatile directing groups for $\mathrm{C}-\mathrm{H}$ bond functionalisation, and various transformations employing $N$-alkoxyamides are currently available. ${ }^{4}$ While $\mathrm{N}$-alkoxyamides are commonly used in various organic reactions, the dealkoxylation of $N$-alkoxyamides has not been explored enough yet (Scheme 1b).

Conventional dealkoxylation of $\mathrm{N}$-alkoxyamides requires stoichiometric metal-based reductants such as $\mathrm{SmI}_{2},{ }^{5} \mathrm{Na} / \mathrm{Hg}^{6}$ and lithium powder ${ }^{7}$ (Scheme 2a). An organic, neutral super electron donor has been developed as a stoichiometric reductant, and it gives results comparable to those obtained using metal-based reductants. ${ }^{8}$ Base-mediated formal reduction of $\mathrm{N}$-alkoxyamides has also evolved as a method for dealkoxylation. ${ }^{9}$ Treatment of $N$-alkoxyamides with lithium diisopropylamide, ${ }^{9 a}$ or tert-butyldimethylsilyl triflate and triethylamine ${ }^{9 b}$

Department of Applied Chemistry, Tokyo University of Science, 1-3 Kagurazaka, Shinjuku-ku, Tokyo 162-8601, Japan.E-mail: mtd@rs.tus.ac.jp

$\dagger$ Electronic supplementary information (ESI) available: Experimental procedures and characterisation data for new compounds. See DOI: 10.1039/d0ob01815e resulted in the formal reduction of the amides, along with the formation of formaldehyde. Although these reductants and bases allow facile cleavage of the alkoxy groups from $\mathrm{N}$-alkoxyamides under very mild conditions, excess amounts of reductants or bases are required for these reactions. In

(a) Used as acylating reagent - Well investigated

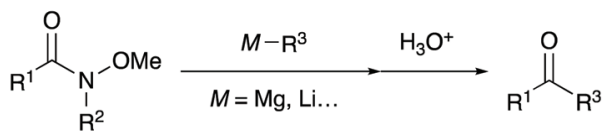

(b) Reductive N-O bond cleavage - Less investigated

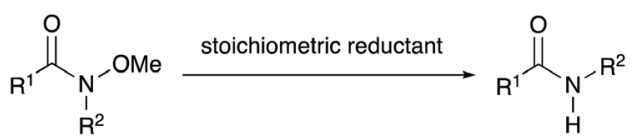

Scheme 1 Transformation of $N$-alkoxyamides: (a) nucleophilic addition of organometallic reagents and (b) dealkoxylation of $N$-alkoxyamides.

(a) Stoichiometric reaction

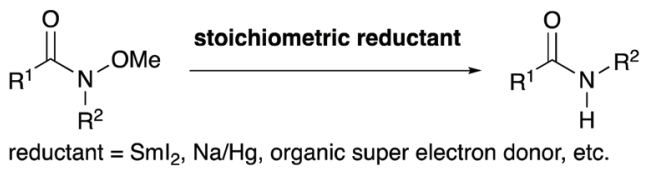

(b) Transition metal-catalysed reaction

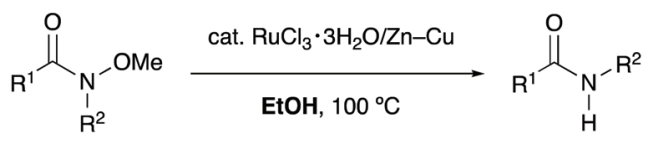

(c) This work

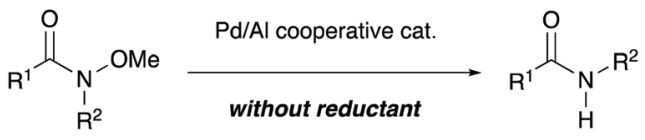

Scheme 2 Dealkoxylation of $\mathrm{N}$-alkoxyamides. 
addition, these reducing reagents are sometimes expensive, difficult to handle, and hazardous. Ruthenium-catalysed dealkoxylation of $\mathrm{N}$-alkoxyamides has been reported as an alterna-

Table 1 Optimisation of reaction conditions ${ }^{a}$

\begin{tabular}{|c|c|c|c|}
\hline & Me & $\begin{array}{l}4 \mathrm{~mol} \% \mathrm{Pd}(\mathrm{dba})_{2} \\
4 \mathrm{~mol} \% \mathrm{DPPBB} \\
10 \mathrm{~mol} \% \text { Lewis acid } \\
\text { solvent, } 150^{\circ} \mathrm{C}, 6 \mathrm{~h}\end{array}$ & \\
\hline Entry & Lewis acid & Solvent & Yield (\%) \\
\hline 1 & - & Toluene & 33 \\
\hline 2 & $\mathrm{AlCl}_{3}$ & Toluene & NR \\
\hline 3 & $\mathrm{AlMe}_{3}$ & Toluene & 87 \\
\hline 4 & $\mathrm{Al} i-\mathrm{Bu}_{3}$ & Toluene & 98 \\
\hline 5 & $\mathrm{Al}(\mathrm{OEt})_{3}$ & Toluene & 83 \\
\hline 6 & $\mathrm{Al}(\mathrm{O} i-\mathrm{Pr})_{3}$ & Toluene & 94 \\
\hline 7 & $\mathrm{Al} i-\mathrm{Bu}_{3}$ & $p$-Xylene & 86 \\
\hline 8 & $\mathrm{Al} i-\mathrm{Bu}_{3}$ & 1,4-Dioxane & 86 \\
\hline 9 & $\mathrm{Al} i-\mathrm{Bu}_{3}$ & CPME & 99 \\
\hline 10 & $\mathrm{Al} i-\mathrm{Bu}_{3}$ & Diglyme & 85 \\
\hline 11 & $\mathrm{Al} i-\mathrm{Bu}_{3}$ & DMF & 84 \\
\hline 12 & $\mathrm{Al} i-\mathrm{Bu}_{3}$ & DMSO & 61 \\
\hline $13^{b}$ & $\mathrm{Al} i-\mathrm{Bu}_{3}$ & CPME & 99 \\
\hline
\end{tabular}

${ }^{a}$ Reaction conditions: 1 (0.3 mmol), Pd(dba $)_{2}$ (4 mol\%), DPPBz $(4 \mathrm{~mol} \%)$ and Lewis acid $(10 \mathrm{~mol} \%)$ in CPME $(0.3 \mathrm{M})$ at $150^{\circ} \mathrm{C}$ for $6 \mathrm{~h}$, unless otherwise noted. ${ }^{b} \mathrm{Pd}(\mathrm{dba})_{2} / \mathrm{DPPBz}\left(2 \mathrm{~mol} \%\right.$ each) and $\mathrm{Al} i-\mathrm{Bu}_{3}$ ( $5 \mathrm{~mol} \%$ ) were used as catalysts. The reaction time was $20 \mathrm{~h}$. tive protocol for avoiding the use of such stoichiometric reagents (Scheme 2b). Dealkoxylation proceeded in alcoholic solvents, which also behaved as a stoichiometric reductant. ${ }^{10}$ Although the catalytic reactions require only green and cheap alcohols as stoichiometric reductants, it is necessary to add a substoichiometric amount of $\mathrm{Zn}-\mathrm{Cu}$ for activating the ruthenium catalyst. Herein, we report the palladium-catalysed dealkoxylation of $\mathrm{N}$-alkoxyamides in the absence of an external reductant as a convenient and reductant-free protocol for dealkoxylation (Scheme 2c). To the best of our knowledge, this is the first report on the catalytic dealkoxylation of $\mathrm{N}$-alkoxyamides without any external reductants. ${ }^{11}$

We began our investigation using $N$-methoxy- $N$-methylbenzamide (1a) as a model substrate, which was heated in toluene at $150{ }^{\circ} \mathrm{C}$ in the presence of the $\mathrm{Pd}(\mathrm{dba})_{2} / \mathrm{DPPBz}$ catalyst (Table 1). After $6 \mathrm{~h}$, the desired secondary amide $2 \mathrm{a}$ was formed in a moderate yield (entry 1 ). We then screened aluminium Lewis acids as co-catalysts in order to activate the $\mathrm{N}-\mathrm{O}$ bond. ${ }^{12}$ The addition of aluminium(III) chloride $\left(\mathrm{AlCl}_{3}\right)$ suppressed the reaction completely (entry 2). Trialkylaluminium or trialkoxyaluminium dramatically improved the yields (entries 3-6), and the best result was obtained when triisobutylaluminium $\left(\mathrm{Al} i-\mathrm{Bu}_{3}\right)$ was employed as a co-catalyst (entry 4). ${ }^{13}$ Solvent screening (entries 7-12) revealed that cyclopentyl methyl ether (CPME) was the optimal solvent for affording the desired product in an excellent yield (entry 9). ${ }^{14}$ In addition, this demethoxylation reaction could reach completion with reduced catalyst loadings (entry 13).

Table 2 Palladium-catalysed demethoxylation of $N$-methoxyamides ${ }^{a}$
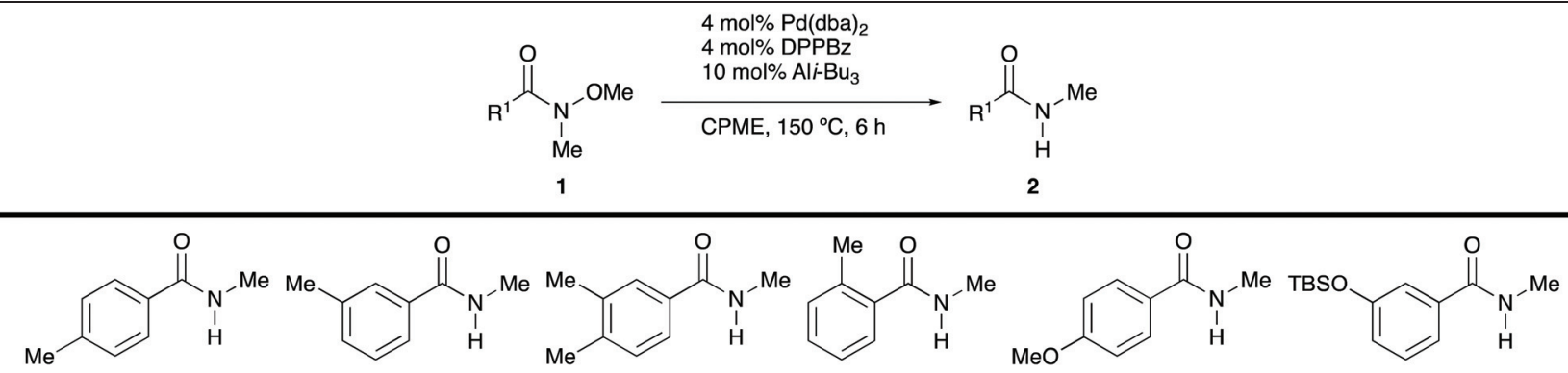

2b $87 \%$

2c $93 \%$

2d $96 \%$

$2 e 8 \%^{b}$

2f $90 \%$

$2 \mathrm{~g} 97 \%^{c}$<smiles>CNC(=O)c1ccc(C(F)(F)F)cc1</smiles>

2h $91 \%$<smiles>CNC(=O)c1ccc(F)cc1</smiles>

2i $94 \%$<smiles>O=C(NC(=O)[N+]([O-])([O-])[O-])c1ccco1</smiles>

2n $80 \%$<smiles>CNC(=O)c1cccs1</smiles>

$2093 \%$<smiles>NC(=O)c1ccc(Cl)cc1</smiles>
2j $52 \%^{b}$<smiles>CNC(=O)c1ccncc1</smiles>

2k $67 \%$<smiles>NNC(=O)c1cccnc1</smiles>

21 $80 \%$<smiles>CNC(=O)/C=C/c1ccccc1</smiles>

2p $70 \%^{b}$<smiles>CNC(=O)CCc1ccccc1</smiles>

2q $80 \%^{b}$<smiles>CNC(=O)CCCc1ccccc1</smiles>

2r $85 \%^{d}$<smiles>CNC(=O)c1ccccn1</smiles>

$2 m 62 \%$<smiles>CNC(=O)C1CCCCC1</smiles>

2s $79 \%^{b}$

${ }^{a}$ Reaction conditions: 1 ( $\left.0.3 \mathrm{mmol}\right), \mathrm{Pd}(\mathrm{dba})_{2}$ (4 mol\%), DPPBz (4 mol\%) and $\mathrm{Ali}-\mathrm{Bu}_{3}(10 \mathrm{~mol} \%)$ in CPME $(0.3 \mathrm{M})$ at $150{ }^{\circ} \mathrm{C}$ for $6 \mathrm{~h}$, unless otherwise noted. The yields represent the average yield of two reaction runs. ${ }^{b} \mathrm{Pd}(\mathrm{dba})_{2}(8 \mathrm{~mol} \%), \mathrm{DPPBz}(8 \mathrm{~mol} \%)$ and $\mathrm{Ali}-\mathrm{Bu} \mathrm{B}_{3}(20 \mathrm{~mol} \%)$ were used $(20 \mathrm{~h}) .{ }^{c}$ The reaction time was $18 \mathrm{~h} .{ }^{d} \mathrm{Pd}(\mathrm{dba})_{2}(8 \mathrm{~mol} \%)$, DPPBz $(8 \mathrm{~mol} \%)$ and $\mathrm{Al} i-\mathrm{Bu}_{3}(20 \mathrm{~mol} \%)$ were used $(18 \mathrm{~h})$. 
With the optimised reaction conditions in hand, we investigated the scope of demethoxylation (Table 2). Introduction of methyl groups at the para- and meta-positions of the benzene ring (1)-d) did not affect the efficiency of transformations. However, the reactivity decreased with $o$-methylbenzamide 1e, and increased catalyst loadings were required to obtain a reasonable yield of the desired secondary amide. Benzamides

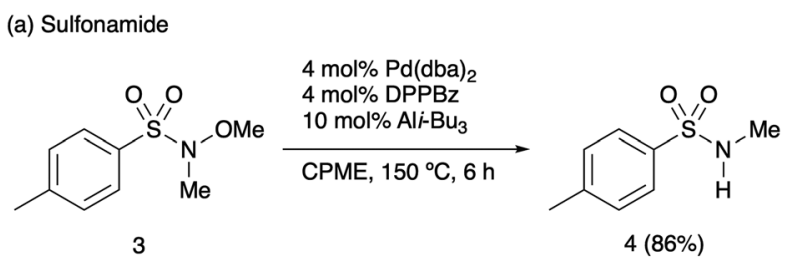

(b) Phsphoramide

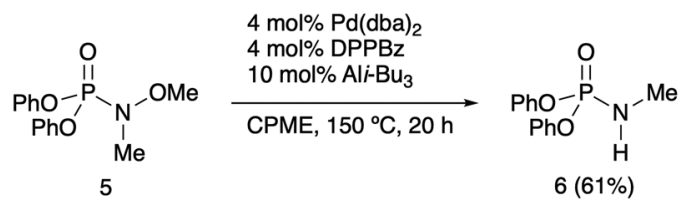

Scheme 3 Palladium-catalysed demethoxylation of sulfonamide 3 and phosphoramidate 5 .

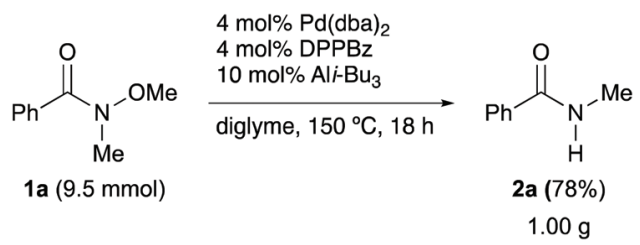

Scheme 4 A gram-scale reaction.

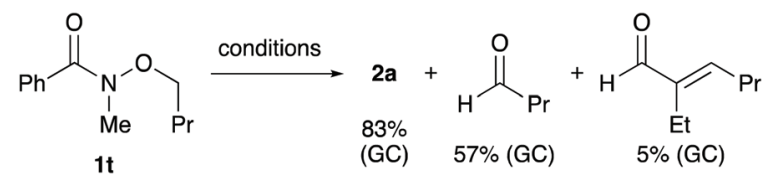

Scheme 5 Palladium-catalysed debutoxylation of $N$-butoxy- $N$-methylbenzamide (1t) (conditions: 4 mol\% Pd(dba) 2,4 mol\% DPPBz, $10 \mathrm{~mol} \%$ $\left.\mathrm{Ali}-\mathrm{Bu}_{3}, \mathrm{CPME}, 150^{\circ} \mathrm{C}, 6 \mathrm{~h}\right)$. bearing electron-donating and electron-withdrawing groups 1f-j were well tolerated under the optimal conditions. Heteroaryl-substituted substrates $\mathbf{1 k - 0}$ were also converted into the desired secondary amides with high efficiency. Cinnamamide 1p afforded the corresponding product without the reduction of the olefin moiety. ${ }^{10}$ It is worth noting that the demethoxylation of enolisable $N$-methyl- $N$-methoxyamides 1qs proceeded smoothly, and no side reactions were observed.

To further demonstrate the applicability of demethoxylation, other alkoxyamides were examined. Under the optimal conditions, sulfonamide 3 gave the desired secondary sulfonamide 4 in a high yield (Scheme 3a). Moreover, phosphoramidate 5 was found to be a promising substrate for the demethoxylation to afford the corresponding product in a good yield (Scheme $3 \mathrm{~b}$ ). In both cases, an $\mathrm{N}-\mathrm{O}$ bond was selectively cleaved, while the other heteroatom-heteroatom bonds remained intact. In contrast to previous studies, reductant-free demethoxylation was applicable to a wide range of $N$-methoxy$\mathrm{N}$-methylamides, without the occurrence of any side reactions or over-reactions. Furthermore, a gram-scale reaction was performed with $\mathbf{1 a}$ in diglyme, and the desired product $\mathbf{2 a}$ was obtained in $78 \%$ yield (Scheme 4 ). ${ }^{15}$

To gain insight into the reaction mechanism, a control experiment was conducted (Scheme 5). When $N$-butoxy- $N$ methylbenzamide (1t) was subjected to the standard reaction conditions, butanal and its aldol condensation product were produced along with the desired secondary amide 2a. These byproducts may have been generated via the $\beta$-hydrogen elimination from a palladium alkoxide intermediate. The results reveal that an $\alpha$-hydrogen atom with respect to the oxygen atom of the alkoxy group functions as a hydride source. ${ }^{11,16}$

A plausible mechanism for the reductant-free demethoxylation is proposed on the basis of a previous report ${ }^{11}$ and our preliminary mechanistic investigations (Scheme 6). The carbonyl oxygen of alkoxyamide $\mathbf{1}$ coordinates to the aluminium Lewis acid to form $\mathbf{A}$, thereby weakening the $\mathrm{N}-\mathrm{O}$ bond. Subsequently, oxidative addition of the $\mathrm{N}-\mathrm{O}$ bond to $\mathrm{Pd}(0)$ generates palladium alkoxide $\mathbf{B}$, which undergoes $\beta$-hydrogen elimination to generate palladium hydride intermediate $\mathbf{C}$ and formaldehyde. Finally, reductive elimination from the intermediate $\mathbf{C}$ affords secondary amide $\mathbf{2}$ and simultaneously regenerates the catalytically active $\operatorname{Pd}(0)$ species.

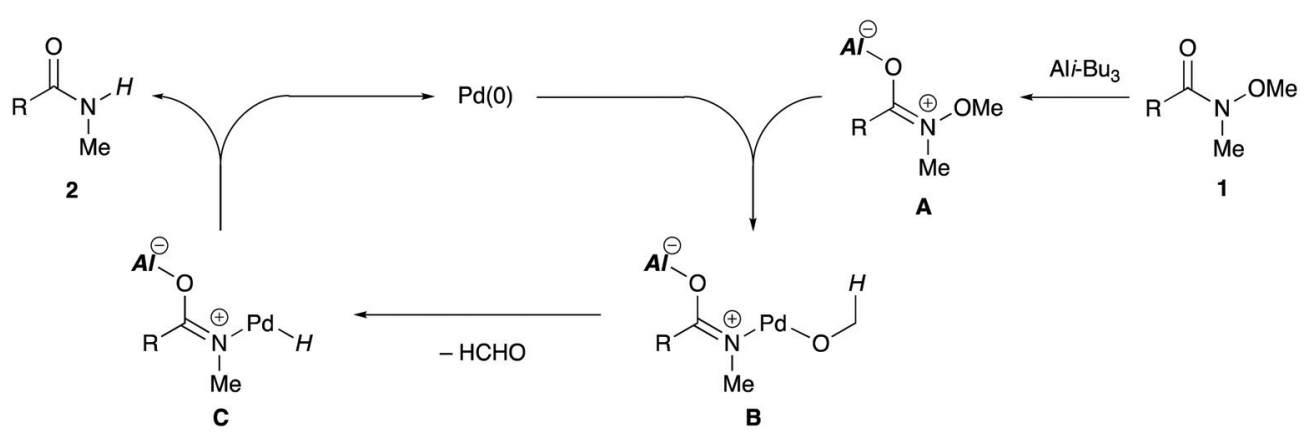

Scheme 6 The plausible reaction mechanism for reductant-free demethoxylation. 


\section{Conclusions}

In summary, we achieved the demethoxylation of $N$-alkoxyamides in the presence of a $\mathrm{Pd} / \mathrm{Al}$ cooperative catalytic system. The reaction proceeded with various $\mathrm{N}$-alkoxyamides including a sulfonamide and a phosphoramide in the absence of an external reductant. The $\mathrm{N}-\mathrm{O}$ bond was selectively reduced, and there were no side reactions or over-reactions. Preliminary mechanistic investigations revealed that $\beta$-hydrogen elimination of a palladium alkoxide intermediate generated an intramolecular hydride source. Further studies on palladium-catalysed reductant-free demethoxylation are ongoing in our laboratory.

\section{Conflicts of interest}

There are no conflicts to declare.

\section{Notes and references}

1 S. Balasubramaniam and I. S. Aidhen, Synthesis, 2008, 3707-3738.

2 (a) S. Nahm and S. M. Weinreb, Tetrahedron Lett., 1981, 22, 3815-3818; (b) J. A. Murphy, A. G. J. Commeureuc, T. N. Snaddon, T. M. McGuire, T. A. Khan, K. Hisler, M. L. Dewis and R. Carling, Org. Lett., 2005, 7, 1427-1429; (c) C. O. Kangani, D. E. Kelley and B. W. Day, Tetrahedron Lett., 2006, 47, 6289-6292.

3 (a) A. Basha, M. Lipton and S. M. Weinreb, Tetrahedron Lett., 1977, 18, 4171-4172; (b) J. M. Williams, R. B. Jobson, N. Yasuda, G. Marchesini, U.-H. Dolling and E. J. J. Grabowski, Tetrahedron Lett., 1995, 36, 5461-5464; (c) T. Shimizu, K. Osako and T. Nakata, Tetrahedron Lett., 1997, 38, 2685-2688; (d) P.-Q. Huang, X. Zheng and X.-M. Deng, Tetrahedron Lett., 2001, 42, 9039-9041.

4 (a) F. Yang and L. Ackermann, Org. Lett., 2013, 15, 718-720;

(b) Y. Wang, C. Li, Y. Li, F. Yin and X.-S. Wang, Adv. Synth. Catal., 2013, 355, 1724-1728; (c) G. Li, L. Wan, G. Zhang, D. Leow, J. Spangler and J.-Q. Yu, J. Am. Chem. Soc., 2015, 137, 4391-4397; (d) R. Das and M. Kapur, Chem. - Asian J., 2015, 10, 1505-1512; (e) R. Das and M. Kapur, Chem. - Eur. J., 2016, 22, 16986-16990; $(f)$ K. Kawai, Y. Bunno, T. Yoshino and S. Matsunaga, Chem. - Eur. J., 2018, 24, 10231-10237.

5 (a) J. L. Chiara, C. Destabel, P. Gallego and J. MarcoContelles, J. Org. Chem., 1996, 61, 359-360; (b) G. E. Keck,
S. F. McHardy and J. E. Murry, J. Am. Chem. Soc., 1995, 117, 7289-7290.

6 (a) R. Sword, S. O'Sullivan and J. A. Murphy, Aust. J. Chem., 2013, 66, 314-322; (b) J. E. Jackson, B. N. O’Brien, S. K. Kedzior, G. R. Fryz, F. S. Jalloh, A. Banisafar, M. A. Caldwell, M. B. Braun, B. M. Dunyak and J. L. Dye, Tetrahedron Lett., 2015, 56, 6227-6230.

7 M. Yus, G. Radivoy and F. Alonso, Synthesis, 2001, 914-918.

8 S. P. Y. Cutulic, J. A. Murphy, H. Farwaha, S.-Z. Zhou and E. Chrystal, Synlett, 2008, 2132-2136.

9 (a) S. L. Graham and T. H. Scholz, Tetrahedron Lett., 1990, 31, 6269-6272; (b) G. E. Keck, S. F. McHardy and J. A. Murry, Tetrahedron Lett., 1993, 34, 6215-6218.

10 H. Fukuzawa, Y. Ura and Y. Kataoka, J. Organomet. Chem., 2011, 696, 3643-3648.

11 For nickel-catalysed reductant-free dealkoxylation of aryl alkyl ethers, see: M. Tobisu, T. Morioka, A. Ohtsuki and N. Chatani, Chem. Sci., 2015, 6, 3410-3414.

12 For the decrease in the activation energy of an aryl $\mathrm{C}-\mathrm{O}$ bond cleavage by aluminium Lewis acids, see: (a) X. Liu, C.-C. Hsiao, I. Kalvet, M. Leiendecker, L. Guo, F. Schoenebeck and M. Rueping, Angew. Chem., Int. Ed., 2016, 55, 6093-6098; (b) P. Kelley, G. A. Edouard, S. Lin and T. Agapie, Chem. - Eur. J., 2016, 22, 17173-17176.

13 For recent examples of transition metal/aluminium cooperative catalysis, see: $(a)$ P. A. Donets and N. Cramer, J. Am. Chem. Soc., 2013, 135, 11772-11775; (b) S. Okumura, S. Tang, T. Saito, K. Semba, S. Sakaki and Y. Nakao, J. Am. Chem. Soc., 2016, 138, 14699-14704; (c) S. Okumura and Y. Nakao, Org. Lett., 2017, 19, 584-587; (d) F. Inoue, T. Saito, K. Semba and Y. Nakao, Chem. Commun., 2017, 53, 4497-4500; (e) Q.-S. Liu, D.-Y. Wang, Z.-J. Yang, Y.-X. Luan, J.-F. Yang, J.-F. Li, Y.-G. Pu and M. Ye, J. Am. Chem. Soc., 2017, 139, 18150-18153; ( $f$ ) S. Okumura, T. Komine, E. Shigeki, K. Semba and Y. Nakao, Angew. Chem., Int. Ed., 2018, 57, 929-932; (g) Y.-X. Wang, S.-L. Qi, Y.-X. Luan, X.-W. Han, S. Wang, H. Chen and M. Ye, J. Am. Chem. Soc., 2018, 140, 5360-5364; (h) T. Zhang, Y.-X. Luan, S.-J. Zheng, Q. Peng and M. Ye, Angew. Chem., 2020, 59, 7439-7443.

14 The yield was dramatically decreased when the reaction was performed at $130{ }^{\circ} \mathrm{C}$ for $6 \mathrm{~h}$ (36\% yield).

15 The solvent was employed in order to perform the reaction in a flask.

16 (a) X. Wu, B. P. Fors and S. L. Buchwald, Angew. Chem., Int. Ed., 2011, 50, 9943-9947; (b) M. S. Mikus, C. Sanchez, C. Fridrich and J. F. Larrow, Adv. Synth. Catal., 2020, 362, 430-436. 